\title{
Brittle Creep Failure, Critical Behavior, and Time-to-Failure Prediction of Concrete under Uniaxial Compression
}

\author{
Yingchong Wang, ${ }^{1}$ Na Zhou, ${ }^{1}$ Fuqing Chang, ${ }^{1}$ and Shengwang Hao ${ }^{1,2}$ \\ ${ }^{1}$ School of Civil Engineering and Mechanics, Yanshan University, Qinhuangdao 066004, China \\ ${ }^{2}$ The State Key Laboratory of Nonlinear Mechanics, Institute of Mechanics, Chinese Academy of Science, Beijing, China \\ Correspondence should be addressed to Shengwang Hao; hsw@ysu.edu.cn
}

Received 12 April 2015; Revised 12 June 2015; Accepted 14 June 2015

Academic Editor: João M. P. Q. Delgado

Copyright (c) 2015 Yingchong Wang et al. This is an open access article distributed under the Creative Commons Attribution License, which permits unrestricted use, distribution, and reproduction in any medium, provided the original work is properly cited.

\begin{abstract}
Understanding the time-dependent brittle deformation behavior of concrete as a main building material is fundamental for the lifetime prediction and engineering design. Herein, we present the experimental measures of brittle creep failure, critical behavior, and the dependence of time-to-failure, on the secondary creep rate of concrete under sustained uniaxial compression. A complete evolution process of creep failure is achieved. Three typical creep stages are observed, including the primary (decelerating), secondary (steady state creep regime), and tertiary creep (accelerating creep) stages. The time-to-failure shows sample-specificity although all samples exhibit a similar creep process. All specimens exhibit a critical power-law behavior with an exponent of $-0.51 \pm$ 0.06 , approximately equal to the theoretical value of $-1 / 2$. All samples have a long-term secondary stage characterized by a constant strain rate that dominates the lifetime of a sample. The average creep rate expressed by the total creep strain over the lifetime $\left(t_{f}-t_{0}\right)$ for each specimen shows a power-law dependence on the secondary creep rate with an exponent of -1 . This could provide a clue to the prediction of the time-to-failure of concrete, based on the monitoring of the creep behavior at the steady stage.
\end{abstract}

\section{Introduction}

When concrete is subjected to sustained loading, it exhibits the phenomenon of creep. This phenomenon has been recognized long time ago by both structural and material engineers. Creep behavior of concrete is an important phenomenon to be taken into account for evaluating and analyzing the behavior of concrete structures $[1,2]$. General creep trends of concrete have been established and are well known $[1,3]$, and models have been proposed to predict creep in the design of concrete structures [2]. However, despite major successes, the phenomenon of creep is still far from being fully understood, even though it has occupied some of the best minds in the field of cement and concrete research and materials science [3]. Particularly, most of the work that has been pursued in the area of creep behavior was conducted at low levels of stress [4-6] and early-age creep [7], and the brittle creep behavior of concrete under sustained load levels that are close to its short-term strength is not well known.
Concrete is brittle and under high-sustained loading, creep failure can occur after a certain time $[8,9]$. This behavior is referred to as static fatigue in materials, and it is thus important to understand the behavior of materials. However, whilst this phenomenon has been studied extensively in metals [10], polymer plastic materials, and rocks [11], the time-dependent failure of concrete has been investigated only to a very limited extent. Because of the extensive range of the variety of constituents entering a concrete mix, it is often difficult to make definite comparisons. Efforts have been made in micromechanics of the effect of concrete composition on creep [12]. Viscoelasticity and crack growth govern the long-term deformability of concrete and thus its service behavior and durability [13]. For low-load levels, the viscoelastic behavior appears quasi-linear, and crack growth is inactive. On the other hand, for high-load levels, cracks grow and interact with viscoelasticity [13]. Nevertheless, as noted by researchers the best way to achieve good long-time predictions is to conduct short-time tests on the concrete and 


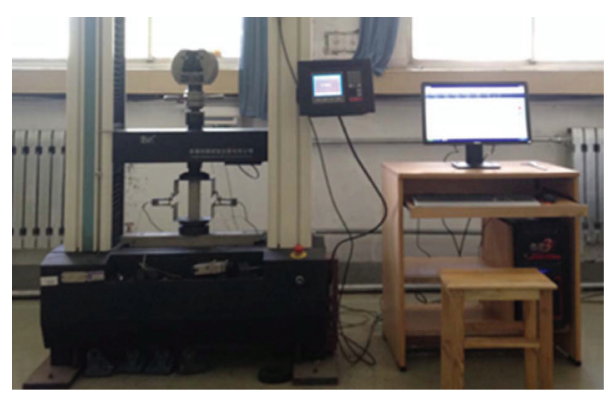

FIgure 1: The test set-up.

then extrapolate them on the basis of a good prediction model incorporating as much as possible of the physics of creep $[3,14]$. Macroscopic scaling laws are necessary if we wish to extrapolate the laboratory results in an attempt to understand the process of brittle creep in concrete at the time-scales and strain rates in practical engineering. The critical behavior of the signals could be a basis for forecasting the time-to-failure of materials [15].

The time-dependent brittle deformation of concrete usually causes concrete to fail under constant stress that is well below its short-term strength over an extended period of time, a process known as brittle creep. The process of creep failure in other brittle materials, such as rock, is typically classified by the following three consecutive stages: primary creep, secondary creep, and accelerating tertiary creep, which is a precursor to failure $[16,17]$. The available literatures [18-21] on creep failure of concrete focus mainly on tensile and flexural creep failure. The creep curves for concrete from tensile and flexural creep tests [8, 22] also display a three-stage process, corresponding to the change in creep rate. The current knowledge of the brittle creep failure behavior of concrete under compression is comparatively not well defined, and it lacks complete experimental results. Nevertheless, it is particularly important for the design and safety assessment of large concrete dams, concrete works in underground engineering, and so on. In these engineering applications, concrete materials are always loaded under long-term compression. It has been shown that basic creep in compression is significantly more important than basic creep in tension [23].

In this paper, through constant uniaxial compression tests for concrete, we discuss three regimes of concrete under constant load and introduce the simple rule between the axial deformation rate of the concrete and the rupture time. This law has an important theoretical and practical significance for predicting concrete creep damage.

\section{Materials and Specimen Preparation}

Each concrete specimen used was a rectangular block, $160 \mathrm{~mm}$ high, $40 \mathrm{~mm} \times 40 \mathrm{~mm}$ in cross section. Each specimen was cast in an accurately machined steel mold. The components of the concrete were silicate cement (28day strength of $42.5 \mathrm{MPa}$ ), natural river sand (fine aggregate), and limestone coarse aggregate (4.75-16 $\mathrm{mm}$ in size). The mixture proportion by weight of cement: water: fine aggregate : coarse aggregate was $1: 0.58: 2.13: 3.80$. The specimens were cured for 28 days in a fog room at $20 \pm 2^{\circ} \mathrm{C}$ and at a relative humidity $(\mathrm{RH}) \geq 95 \%$. The age of loading concrete is about half a year.

\section{Experimental Methodology}

All specimens were uniaxially compressed in the vertical direction (along the $160 \mathrm{~mm}$ axis) at room temperature using a universal electromechanical testing machine, equipped with a load cell with a load step of $1 \mathrm{kN}$. The deformation $u$ of the tested specimens was measured using an extensometer with a resolution of $1 \mu \mathrm{m}$ located on the sides of the specimens. The test set-up is shown in Figure 1.

Before brittle creep experiments, a series of monotonically increasing load experiments was conducted by controlling the monotonic increase of the crosshead displacement of the testing machine in order to obtain the short-term failure characteristics of the concrete. In these experiments, the displacement of the crosshead was the governing displacement that combined the deformation of the loading apparatus and the deformed concrete specimen. The displacement of the crosshead was measured continuously using the linear variable differential transformer (LVDT).

The stress used for the creep tests is determined to be equal to approximately $90 \%$ of the peak stress of the shortterm failure tests. A series of conventional brittle creep experiments were then performed at a predetermined stress. Figure 2 shows the detailed loading process of a sample as an example. We designed the procedure for the brittle creep tests according to the definition of creep. During the tests, all specimens were rapidly loaded to the predetermined stress state with a rate of $5 \mathrm{MPa} / \mathrm{s}$, which is shown in the initial loading phase in Figure 2(a), for the subsequent creep test. The loading was then stopped and the samples were allowed to deform under constant stress (the parts of the creep phases where forces were kept constant in Figure 2(a) until failure). It is shown in Figure 2 that the strain of the samples increased rapidly during the phase of the application of the initial stress. It is clearly indicated that the force is kept constant during the creep phase of the experiment.

\section{Results and Discussions}

4.1. Monotonically Increasing Displacement Experiments. The initial calibration experiments were conducted in order to 


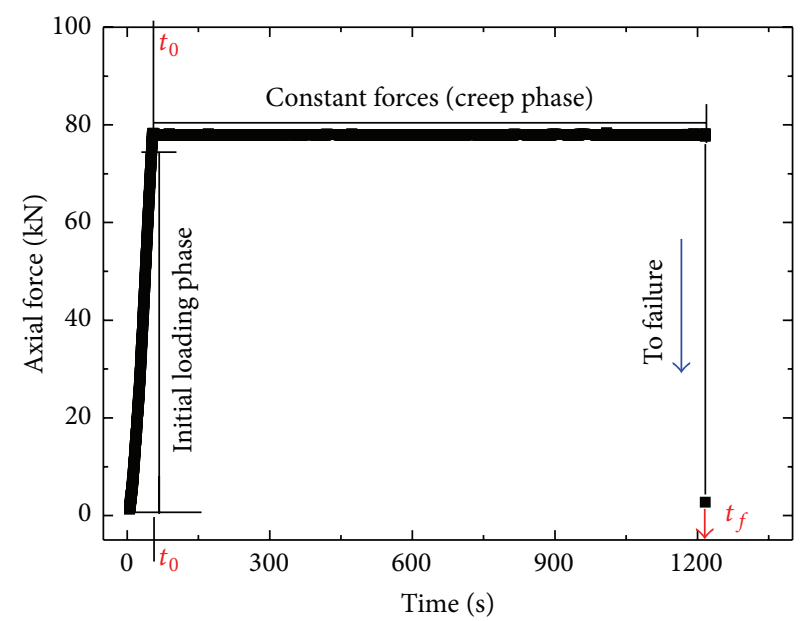

(a)

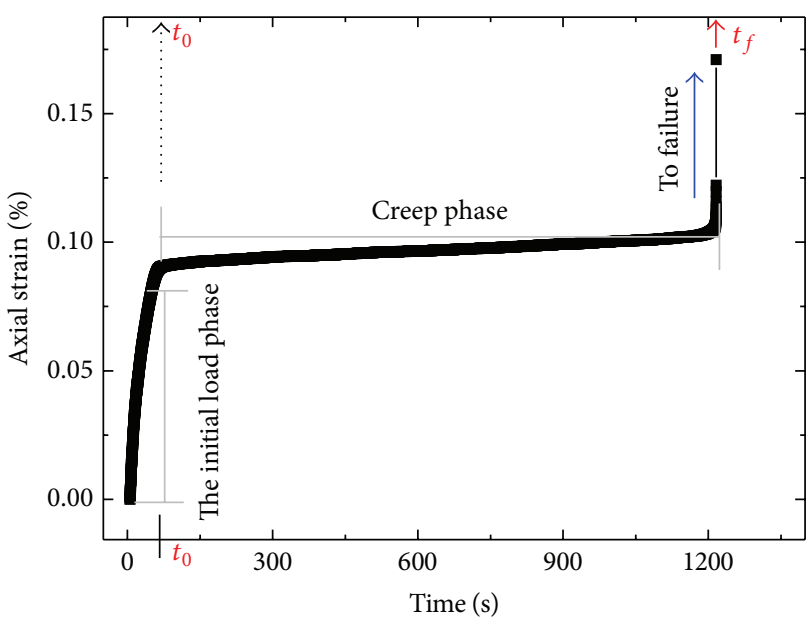

(b)

FIGURE 2: Force-time and strain-time plots of a typical creep experiment on concrete as an example of demonstration of the loading process. (a) The curve of axial force versus time and (b) the curve of the axial strain versus time. It is clear that the load is kept constant during the creep phase. The strain of the sample increases with time at an applied constant force and eventually leads to a sudden macroscopic failure.

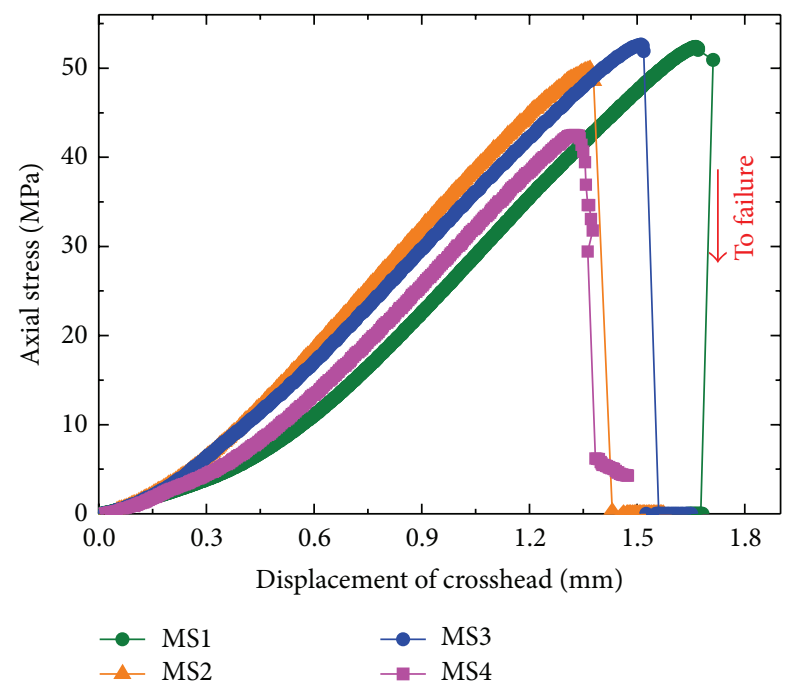

FIGURE 3: Dynamic rupture in concrete (samples are labeled as MS1, MS2, MS3, and MS4) under monotonic loading at a constant displacement rate $(0.05 \mathrm{~mm} / \mathrm{min})$. The specimens fail suddenly in the postfailure stage after the peak force is reached. Concrete exhibits some scatter in the attained peak force and failure strain. In these monotonic tests, the displacements in the brittle creep tests are selected to be the same as those corresponding to the $80-90 \%$ peak forces.

obtain the short-term failure characteristics of the tested concrete materials, using 12 specimens that were compressed by controlling the crosshead displacement, monotonically increasing at a rate of $0.1 \mathrm{~mm} / \mathrm{min}$ until failure (i.e., no-hold step). The sizes and shapes of specimens were the same as those chosen for the creep experiments. Figure 3 shows the representative displacement-stress curves for four concrete specimens as examples.
It can be seen that the concrete specimens exhibit typical stress-strain curves of brittle heterogeneous material like concrete and rock. At a very early stage of the compression test, the stress-displacement curve was slightly convex upwards. Later, an almost linear stress-displacement relation was elicited. The slope of the stress-displacement curve then decreased and after some time it reached the peak stress. Eventually, the specimens failed suddenly at some point in the postfailure stage, after the peak stress. The failure could be attributed to the accumulation and coalescence of microcracks and microdefects. The average peak stress of the 12 specimens was $52.67 \pm 5.51 \mathrm{MPa}$, with a coefficient of variation of 0.10 .

4.2. Brittle Creep Experiments. Brittle creep failure experiments were performed on concrete specimens in order to yield times-to-failure and creep strain rates. The applied stresses in the brittle creep tests were selected to be between $80 \%$ and $90 \%$ of the peak stress in the monotonic tests (Figure 3). As noted above, the detailed loading process of the specimens is shown in Figure 1 as an example.

In brittle creep tests, 11 samples were loaded with different initial stresses during the brittle creep tests. Some samples failed immediately upon the application of the initial stress (these experiments were discarded as they produced no data; some samples did not fail during the available time window of 4 days) and these experiments were also discarded. Following this calibration for the distribution of sample strengths, we conducted four tests with prescribed initial stresses of about $90 \%$ of the peak stress. In order to show the load process and the level of the predetermined stresses for each experiment, curves of the axial stress against time for four samples are shown in Figure 4. It is indicated that all samples failed abruptly after the process of constant stress maintenance. The photographs of failed samples shown in Figure 5 indicate that 


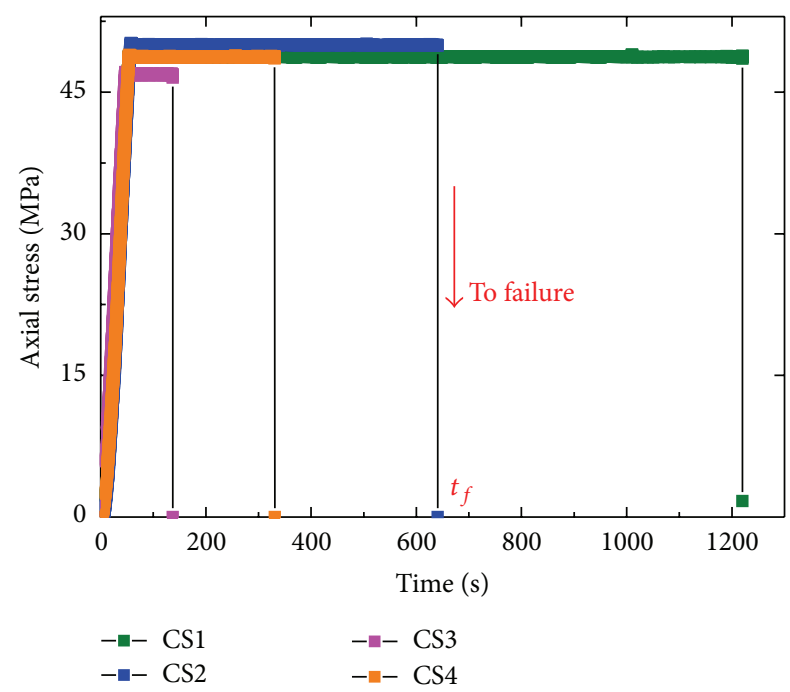

FIgURE 4: Axial stress versus time curves of four concrete samples (labeled as CS1, CS2, CS3, and CS4) during the total loading process, including the initial loading phases and the following creep phases.

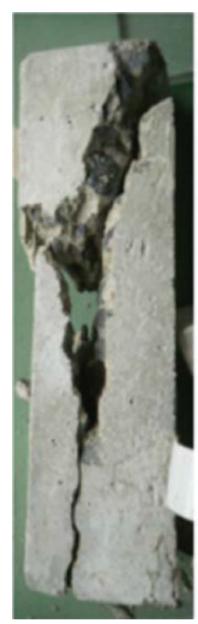

CS1

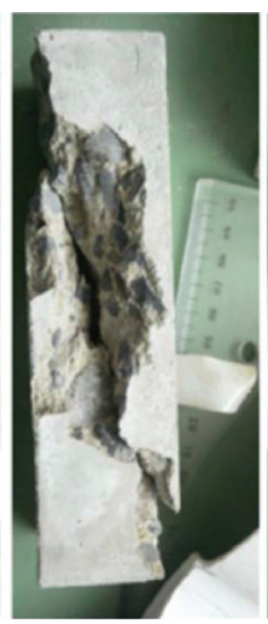

CS2

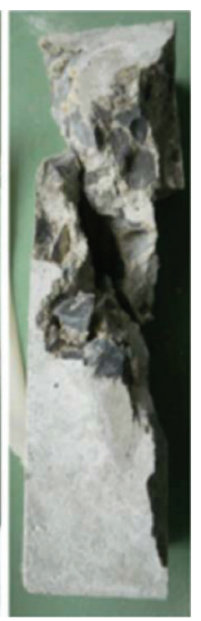

CS3

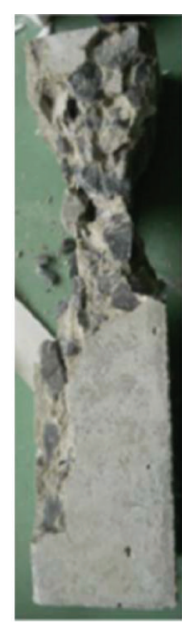

CS4
FIGURE 5: Photos of failed samples in brittle creep experiments.

localization occurred when samples evolved to macroscopic failure.

During the phase where the samples were maintained at a constant stress, concrete exhibited an obvious creep behavior. Figure 4 shows the curves of strain against time for all four samples during the creep phase. It is clear that all curves exhibited the three typical stages of creep that characterize brittle creep deformation. The strain-time curves are characterized by the first stage of primary (transient) creep, followed by the secondary creep and by a stage of tertiary creep.

Each primary creep stage is characterized by an initially high strain rate that decreased with time to reach an almost constant, secondary stage strain rate that is often interpreted as steady creep. Finally, samples entered a tertiary phase that is characterized by an accelerated increase of strain.
This eventually resulted in macroscopic failure of the samples. From Figures 6-7, it is clear that the secondary stage dominated the lifetime of samples.

Further investigation is needed to assess whether a specimen developing steady state creep may fail if the load is sustained for a sufficiently long time. Accelerated strain rate in the tertiary stage can be attributed to the fact that the concrete became weaker and increasingly fractured. In many tests of brittle concrete, the tertiary stage creep was missed owing to the rapid brittle failure of samples at this stage.

In order to further characterize the three stages of the evolution of the properties of concrete's creep failure, the first derivatives of the strain-time curves, that is, the strain rate against time, are calculated and shown in Figure 7 . The plots in Figure 7 demonstrate that there is a long and an almost constant strain rate portion of the curves, as indicated by the horizontal parts of the curves. The steady state creep strain rate can be subsequently calculated within this portion of the creep curve.

4.3. Power-Law Critical Behavior. The acceleration properties that were considered could be used to obtain a short-term prediction for the time-to-failure. Many material failure phenomena, such as volcanoes [24, 25], landslides [26], and laboratory samples [27-29], are preceded by clear accelerating rates of strain [30]. It has been widely suggested [30] that these precursory signals could be the basis for forecasting the time of failure.

The theoretical analysis [31] has shown that the acceleration behavior of the strain rate near failure can be described as a power-law behavior $d \varepsilon / d t \approx A\left(1-t / t_{f}\right)^{-\alpha}$ with an exponent $\alpha=1 / 2$. In this paper, the log-log plots of the axial strain rate versus $\left[1-\left(t-t_{0}\right) /\left(t_{f}-t_{0}\right)\right]$ for the four specimens are shown in Figure 8 , in order to show the critical power-law behavior near failure. The symbol $t_{f}$ represents the failure time, and as noted above, $t_{0}$ is the start time of the creep phase. Consequently, $t_{f}-t_{0}$ is the entire creep time for each concrete specimen. The fitted results (see the red lines in Figures 8(a)-8(b) and the solid blue lines in Figures $6(c)-6(d))$ of the data near failure for each specimen are also shown in Figure 8. It is shown that the creep strain rates near failure for each specimen can be described well by a powerlaw relation; namely, strain rate $=A\left[1-\left(t-t_{0}\right) /\left(t_{f}-t_{0}\right)\right]^{-\alpha}$. The mean power-law exponent was $-\alpha=-0.51 \pm 0.06$, which is almost equal to the theoretical value of $-1 / 2$ [31].

4.4. Dependence of Time-to-Failure on the Secondary Creep Rate. In the brittle creep process, the secondary stage of deformation dominates the entire lifetime of the specimen. In the experiments, a steep creep slope in the secondary stage implies a short lifetime with the lifetime represented by a power-law relationship. The dependence of the lifetime on the creep slope $\lambda_{s}$ of the secondary stage is shown in Figure 9. It is indicated that has exhibited an almost linear relationship with a secondary creep rate $\lambda_{s}$. So, the lifetime $\left(t_{f}-t_{0}\right)$ for each specimen shows a power-law dependence on the secondary creep rate with an exponent of -1 . 


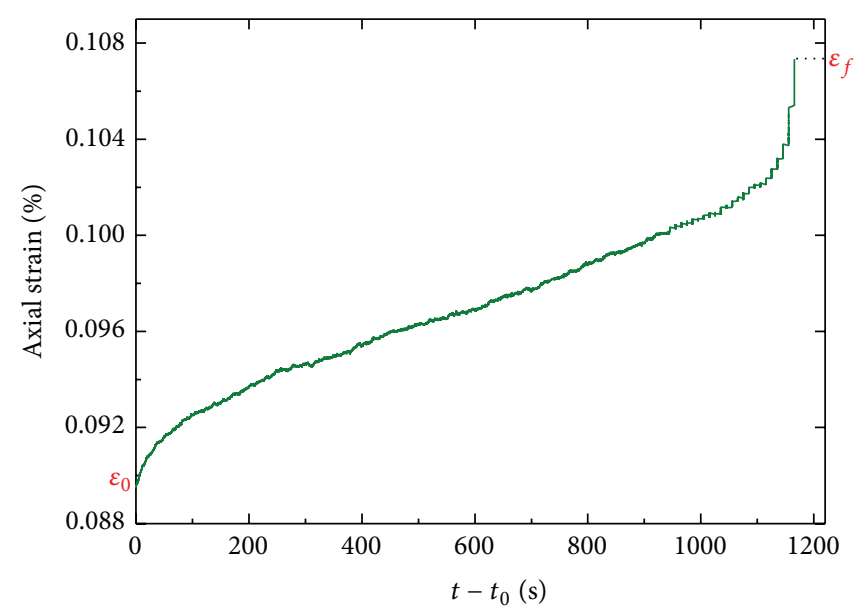

- CS1

(a)

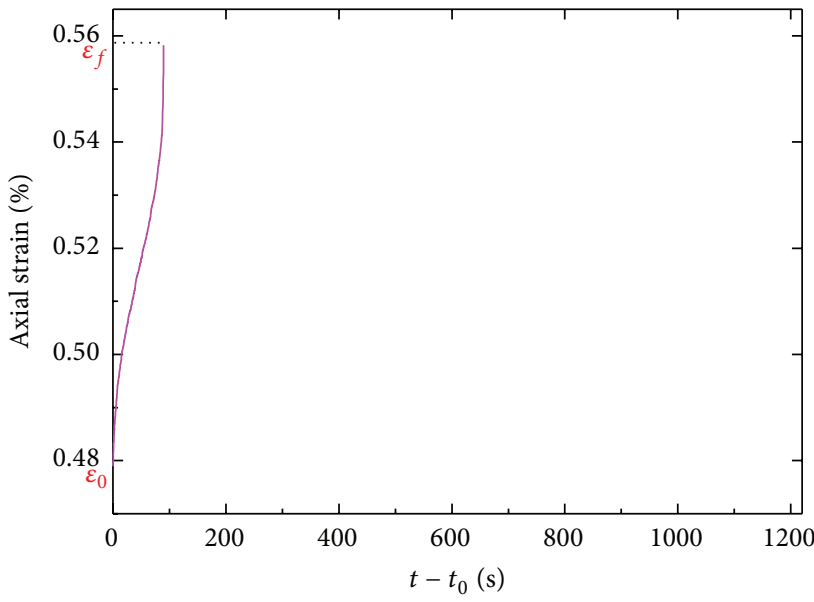

- CS3

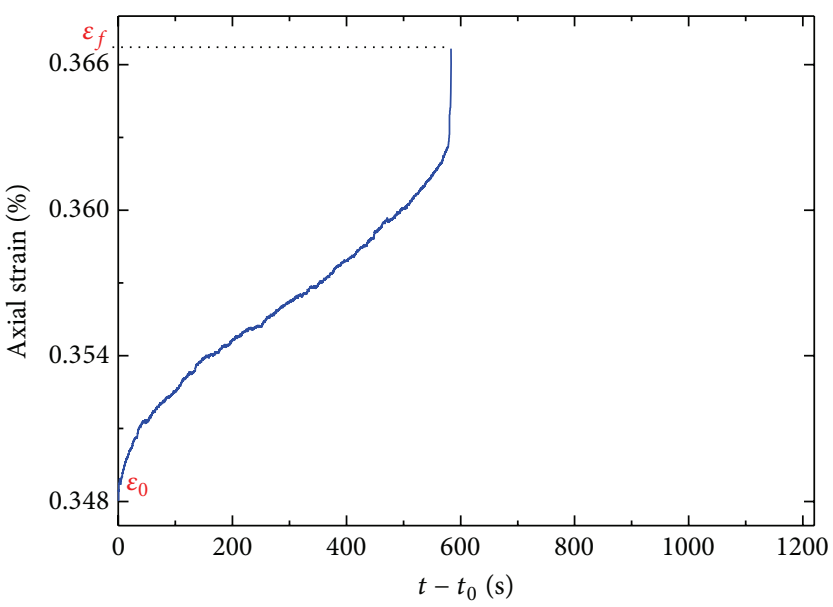

- CS2

(b)

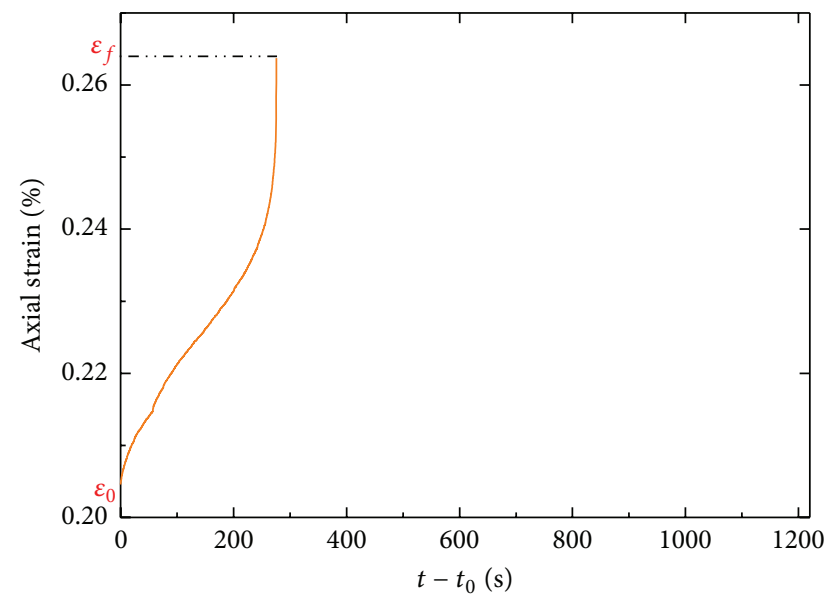

CS4

(c)

(d)

Figure 6: Axial strain versus time curves of four concrete specimens at the creep phases from $t_{0}$ to failure under a constant applied stress. (a) Sample CS1; (b) sample CS2; (c) sample CS3; (d) sample CS4. The curves show the three typical stages of brittle creep: (1) primary (transient) stage characterized by an increasing strain with deceleration, (2) secondary stage, and (3) tertiary stage characterized by accelerating creep.

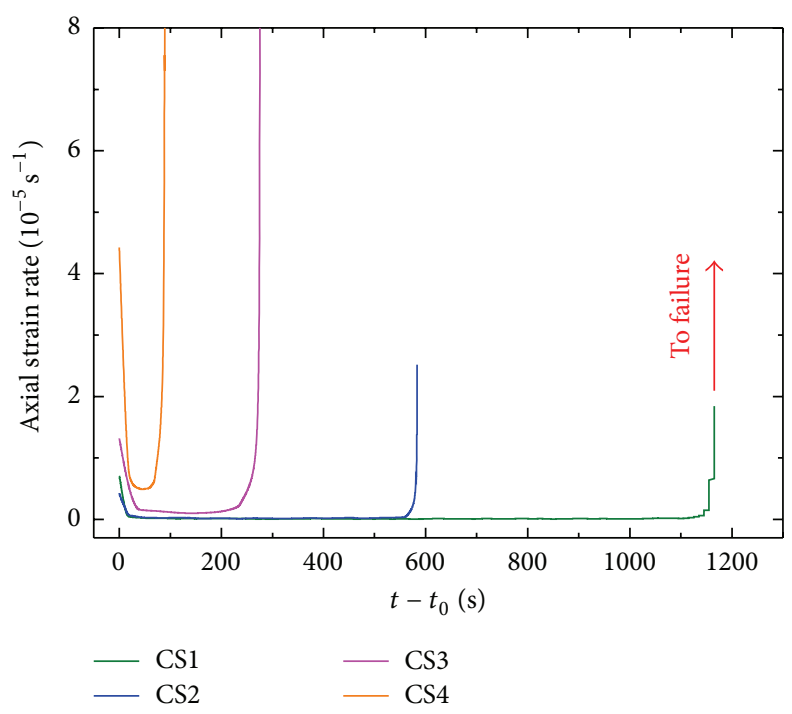

Figure 7: Axial strain rate versus time curves of the four concrete specimens at the creep phases. 


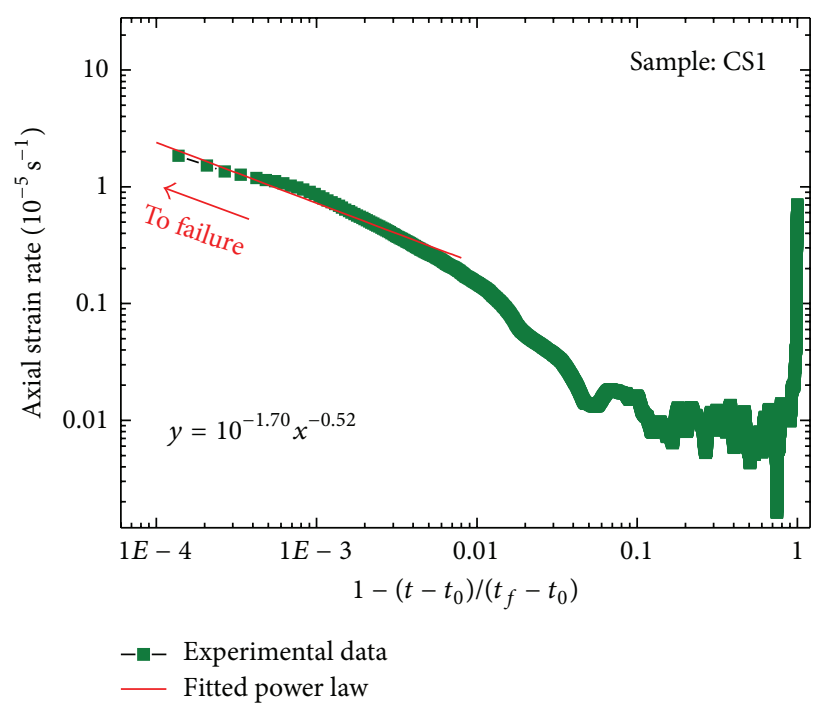

(a)

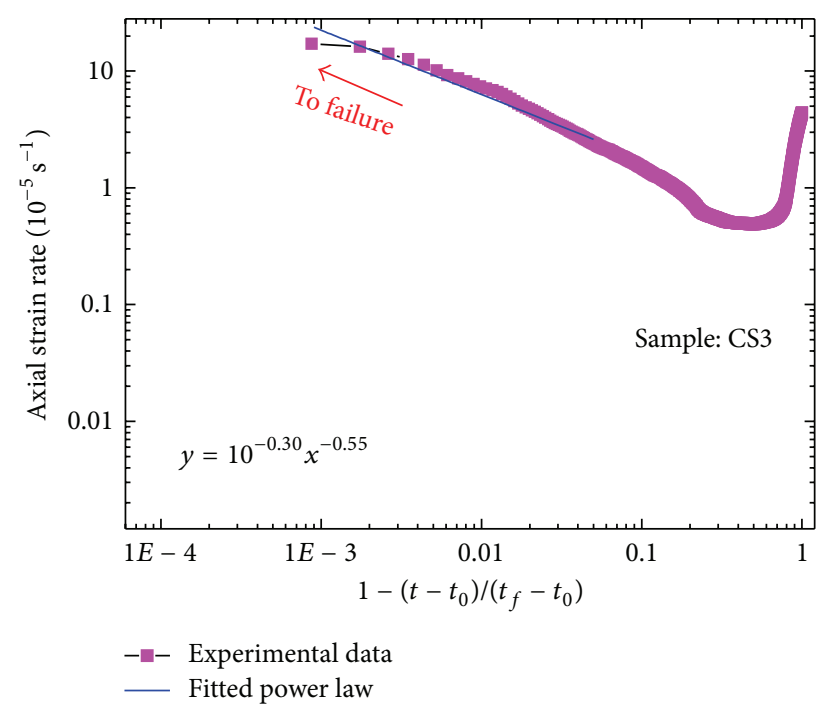

(c)

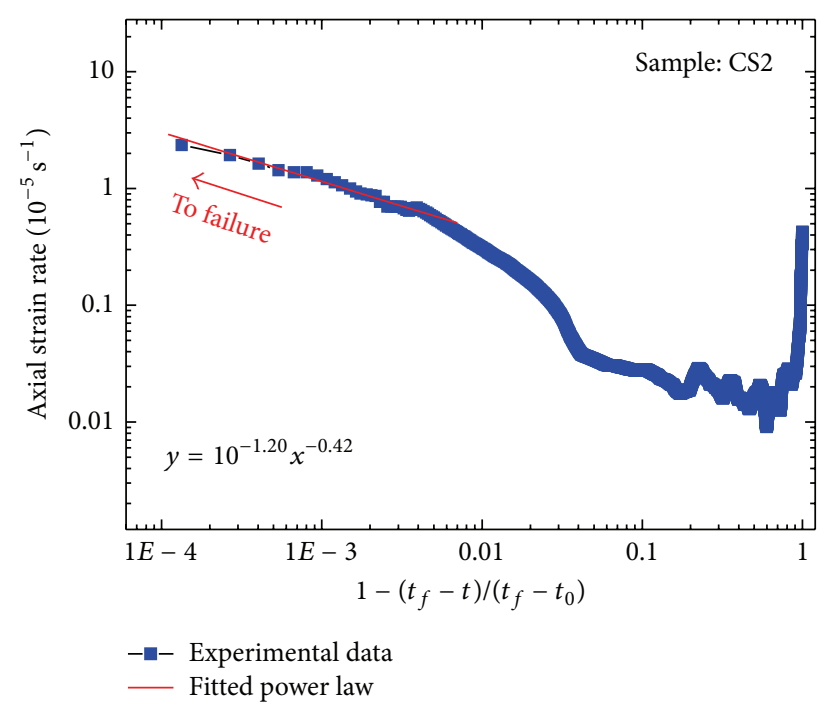

(b)

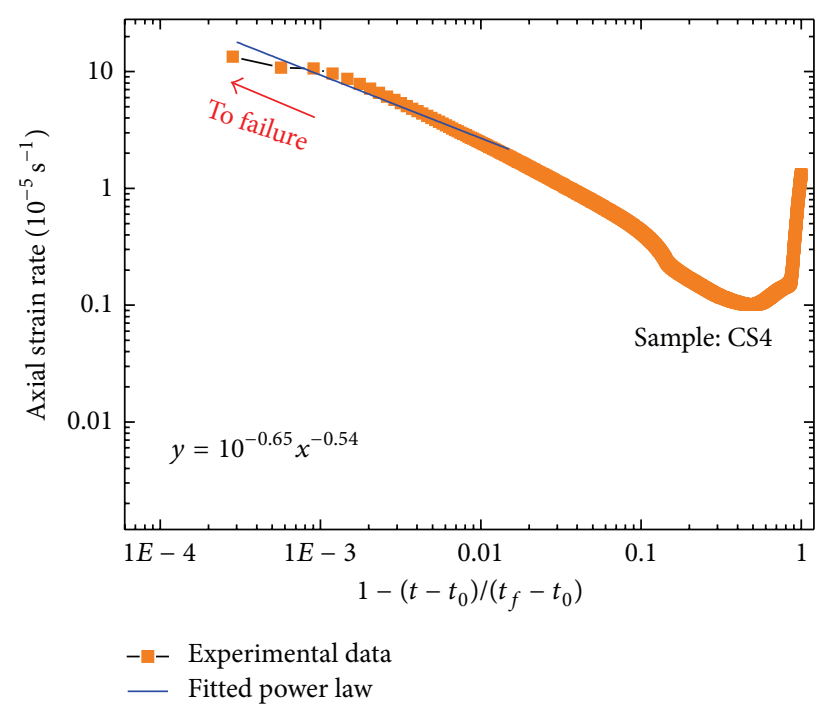

(d)

Figure 8: Log-log plots of axial strain rate against time for four specimens. The power-law fits (see the solid red lines in (a) and (b), and the solid blue lines in $(\mathrm{c})$ and $(\mathrm{d})$ ) to the experimental data near failure are indicated in the figures. The power-law exponent is equal to $-0.51 \pm 0.06$ and it is approximately equal to the theoretical value of $-1 / 2$ quoted in [31].

4.5. Discussions. Brittle failure in concrete is driven by microcrack growth. For low-load levels, crack growth would not occur. However, for high-load levels, crack growth is active and, coupled with viscoelasticity, governs the deformability of concrete and thus its durability. It has been shown $[13,32]$ that models taking crack evolution and the viscoelastic behavior of concrete into consideration can reproduce the experimentally observed trends and explain the effects observed in creep failure tests.

In essence, the evolution of the macroscopic response depends on the microphysical properties and microdamage process of the sample, which induces sample-specificity of time-to-failure. The time-to-failure of concrete samples depends on the sample's microstructure evolution. Variability in the initial microstructures (such as crack density, porosity, and their heterogeneous distribution) could lead to diversification in both creep patterns and time-to-failure among samples deformed under the same loading conditions. Consequently, for a given concrete composition and loading conditions, time-to-failure and creep curves can be highly variable from one sample to another, because of the intrinsic variability of concrete microstructures.

In the present experiments, the difference in the imposed creep stresses was so small that it could not eliminate the effect of sample variability on time-to-failure. Thus, the data from the present creep experiments do not show a strong, direct dependence of time-to-failure on the stress level. In order to fully describe the differences in time-to-failure for various samples as a function of applied stress, it is necessary to perform a series of creep failure experiments over a wider 


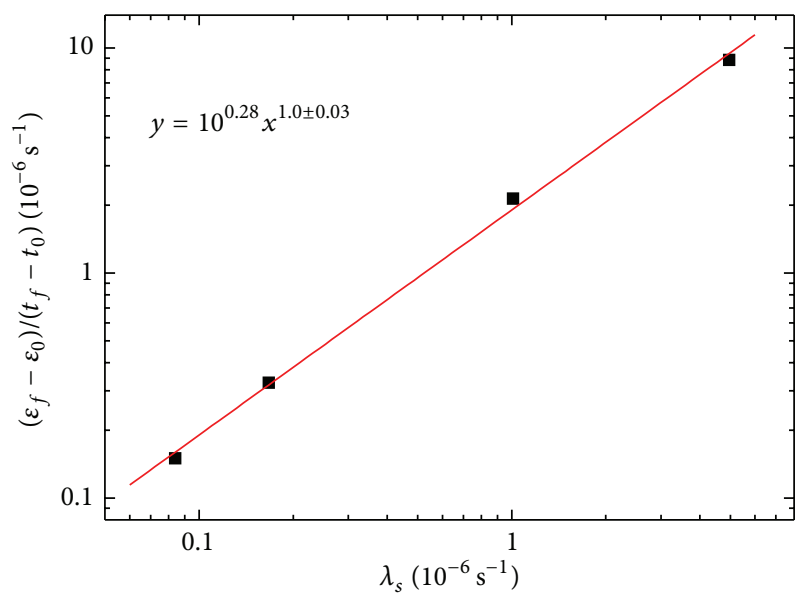

- Experimental data

- Fitted results

FIGURE 9: The log-log plot of the creep slopes $\lambda_{s}$ of the secondary stage and $\left(\varepsilon_{f}-\varepsilon_{0}\right) /\left(t_{f}-t_{0}\right)$. It is indicated that there is an almost linear relation; namely, the solid straight line is the fitted result. So, the lifetime $\left(t_{f}-t_{0}\right)$ for each specimen shows a power-law dependence on the secondary creep rate with an exponent of -1 .

range of imposed creep stresses for which brittle creep failure occurs that are different percentages of the peak stress of the monotonic tests, yielding a range of different times-tofailure. Their eventual macroscopic failure patterns are also different from each other, as shown in Figure 5.

However, the responses obtained do present scaling law patterns, which allow the possibility of extrapolating the laboratory results to understand the processes occurring in actual structures. The reason that the concrete samples exhibit the scaling law is that the sizes of the microdamage events are usually much smaller than those of the eventual macroscopic failure events.

\section{Conclusions}

The experimental data presented in this paper demonstrated that the creep failure of concrete under compression exhibits the three typical evolutionary stages that lead to an eventual macroscopic failure. Samples exhibited sample specificities of the time-to-failure and macroscopic failure patterns but showed similarities in creep process and macroscopic scaling laws.

Concrete specimens tested in the present experiments showed an obvious tertiary stage before the macroscopic failure. The strain rates in the tertiary creep stage of the concrete increased rapidly and led to an acceleration creep. The acceleration creep near failure exhibited a critical powerlaw behavior with an exponent of $-0.51 \pm 0.06$ that was approximately equal to the theoretical value of $-1 / 2$.

The curve of the strain rate against time indicated that there existed a long-term stage where the strain rate sustained a constant value. This implied that the secondary stage with a constant strain rate dominated the lifetime of concrete.
The average creep rate expressed by the total creep strain over the lifetime $\left(t_{f}-t_{0}\right)$ for each specimen showed a power-law dependence on the secondary creep rate with an exponent of -1 . This could provide a clue to the prediction of the timeto-failure of concrete, based on the monitoring of the creep behavior in the steady stage. Also, we can estimate the onset of the third stage based on when the strain rate begins to deviate from the fitted slope of the secondary stage.

\section{Conflict of Interests}

The authors declare that there is no conflict of interests regarding the publication of this paper.

\section{Acknowledgments}

This work is supported by National Basic Research Program of China (Grant 2013CB834100) and Natural Science Foundation of Hebei Province (D2015203398). The authors acknowledge the useful comments of the editor, João M. P. Q. Delgado, and of the anonymous reviewers.

\section{References}

[1] A. D. Ross, "Concrete creep data," Structural Engineer, vol. 15, no. 8, pp. 314-326, 1937.

[2] Z. P. Bažant and S. Baweja, "Justification and refinements of model B3 for concrete creep and shrinkage 1. Statistics and sensitivity," Materials and Structures, vol. 28, no. 7, pp. 415-430, 1995.

[3] Z. P. Bažant, "Prediction of concrete creep and shrinkage: past, present and future," Nuclear Engineering and Design, vol. 203, no. 1, pp. 27-38, 2001.

[4] J. J. Brooks and A. M. Neville, "Comparison of creep, elasticity and strength of concrete in tension and in compression," Magazine of Concrete Research, vol. 29, no. 100, pp. 131-141, 1977.

[5] J. P. Forth, "Predicting the tensile creep of concrete," Cement \& Concrete Composites, vol. 55, pp. 70-80, 2015.

[6] N. Ranaivomanana, S. Multon, and A. Turatsinze, "Basic creep of concrete under compression, tension and bending," Construction and Building Materials, vol. 38, pp. 173-180, 2013.

[7] H. Li, T. H. Wee, and S. F. Wong, "Early-age creep and shrinkage of blended cement concrete," ACI Materials Journal, vol. 99, no. 1, pp. 3-10, 2002.

[8] A. Carpinteri, S. Valente, F. P. Zhou, G. Ferrara, and G. Melchiorri, "Tensile and flexural creep rupture tests on partiallydamaged concrete specimens," Materials and Structures, vol. 30, no. 5, pp. 269-276, 1997.

[9] N. Ranaivomanana, S. Multon, and A. Turatsinze, “Tensile, compressive and flexural basic creep of concrete at different stress levels," Cement and Concrete Research, vol. 52, pp. 1-10, 2013.

[10] R. Fernández and G. González-Doncel, "Understanding the creep fracture behavior of aluminum alloys and aluminum alloy metal matrix composites," Materials Science and Engineering A, vol. 528, no. 28, pp. 8218-8225, 2011.

[11] M. J. Heap, P. Baud, P. G. Meredith, S. Vinciguerra, A. F. Bell, and I. G. Main, "Brittle creep in basalt and its application to timedependent volcano deformation," Earth and Planetary Science Letters, vol. 307, no. 1-2, pp. 71-82, 2011. 
[12] L. P. Granger and Z. P. Bažant, "Effect of composition on basic creep of concrete and cement paste," Journal of Engineering Mechanics, vol. 121, no. 11, pp. 1261-1270, 1995.

[13] E. Denarié, C. Cécot, and C. Huet, "Characterization of creep and crack growth interactions in the fracture behavior of concrete," Cement and Concrete Research, vol. 36, no. 3, pp. 571575, 2006.

[14] Z. P. Bažant, Y. Xi, and S. Baweja, "Improved prediction model for time-dependent deformations of concrete: part 7-Short form of BP-KX model, statistics and extrapolation of short-time data," Materials and Structures, vol. 26, no. 10, pp. 567-574, 1993.

[15] B. Voight, "A relation to describe rate-dependent material failure," Science, vol. 243, no. 4888, pp. 200-203, 1989.

[16] C. H. Scholz, "Mechanism of creep in brittle rock," Journal of Geophysical Research, vol. 73, no. 10, pp. 3295-3302, 1968.

[17] G. N. Boukharov, M. W. Chanda, and N. G. Boukharov, "The three processes of brittle crystalline rock creep," International Journal of Rock Mechanics and Mining Sciences \& Geomechanics Abstracts, vol. 32, no. 4, pp. 325-335, 1995.

[18] J. M. Illston, “The creep of concrete under uniaxial tension," Magazine of Concrete Research, vol. 17, no. 51, pp. 77-84, 1965.

[19] P. L. Domone, "Uniaxial tensile creep and failure of concrete," Magazine of Concrete Research, vol. 26, no. 88, pp. 144-152, 1974.

[20] M. A. Al-Kubaisy and A. G. Young, "Failure of concrete under sustained tension," Magazine of Concrete Research, vol. 27, no. 92, pp. 171-178, 1975.

[21] E. Hamed and M. A. Bradford, "Flexural time-dependent cracking and post-cracking behaviour of FRP strengthened concrete beams," International Journal of Solids and Structures, vol. 49, no. 13, pp. 1595-1607, 2012.

[22] F. Barpi and S. Valente, "Lifetime evaluation of concrete structures under sustained post-peak loading," Engineering Fracture Mechanics, vol. 72, no. 16, pp. 2427-2443, 2005.

[23] P. Rossi, J.-L. Tailhan, and F. le Maou, "Comparison of concrete creep in tension and in compression: influence of concrete age at loading and drying conditions," Cement and Concrete Research, vol. 51, pp. 78-84, 2013.

[24] B. Voight, "A method for prediction of volcanic eruptions," Nature, vol. 332, no. 6160, pp. 125-130, 1988.

[25] B. Voight and R. R. Cornelius, "Prospects for eruption prediction in near real-time," Nature, vol. 350, no. 6320, pp. 695-698, 1991.

[26] D. N. Petley, T. Higuchi, D. J. Petley, M. H. Bulmer, and J. Carey, "Development of progressive landslide failure in cohesive materials," Geology, vol. 33, no. 3, pp. 201-204, 2005.

[27] Y. Lavallée, P. G. Meredith, D. B. Dingwell et al., "Seismogenic lavas and explosive eruption forecasting," Nature, vol. 453, no. 7194, pp. 507-510, 2008.

[28] M. J. Heap, P. Baud, P. G. Meredith, A. F. Bell, and I. G. Main, "Time-dependent brittle creep in darley dale sandstone," Journal of Geophysical Research B: Solid Earth, vol. 114, no. 7, Article ID B07203, 2009.

[29] H. Nechad, A. R. Helmstetter, E. Guerjouma, and D. Sornette, "Andrade creep and critical time-to-failure laws in heterogeneous materials," Physical Review Letters, vol. 94, Article ID 045501, 2005.

[30] A. F. Bell, M. Naylor, M. J. Heap, and I. G. Main, "Forecasting volcanic eruptions and other material failure phenomena: an evaluation of the failure forecast method," Geophysical Research Letters, vol. 38, no. 15, Article ID L15304, 2011.
[31] S.-W. Hao, B.-J. Zhang, and J.-F. Tian, "Relaxation creep rupture of heterogeneous material under constant strain," Physical Review E-Statistical, Nonlinear, and Soft Matter Physics, vol. 85, no. 1, Article ID 012501, 2012.

[32] Y.-N. Li and Z. P. Bažant, "Cohesive crack model with ratedependent opening and viscoelasticity: II. Numerical algorithm, behavior and size effect," International Journal of Fracture, vol. 86, no. 3, pp. 267-288, 1997. 

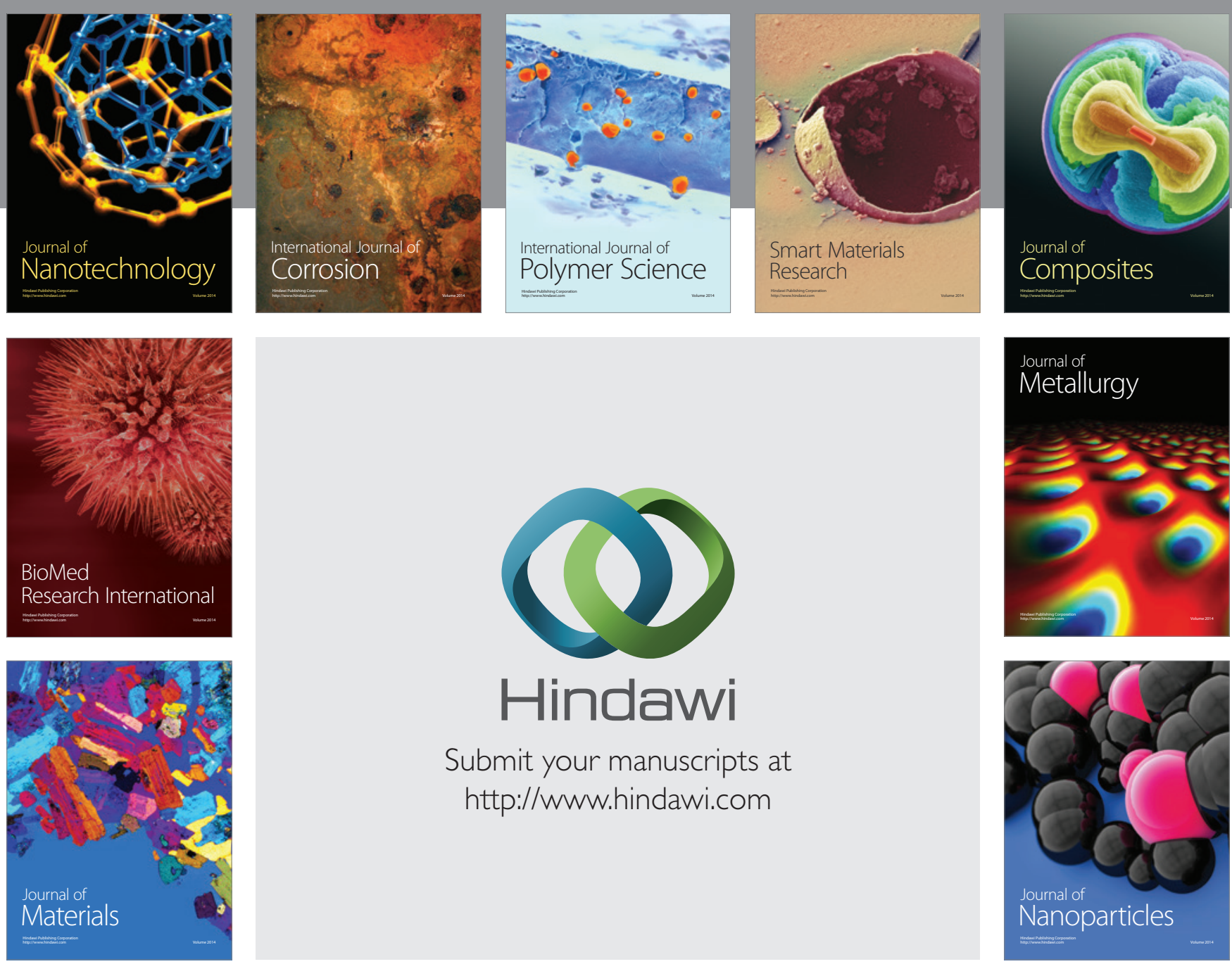

Submit your manuscripts at http://www.hindawi.com
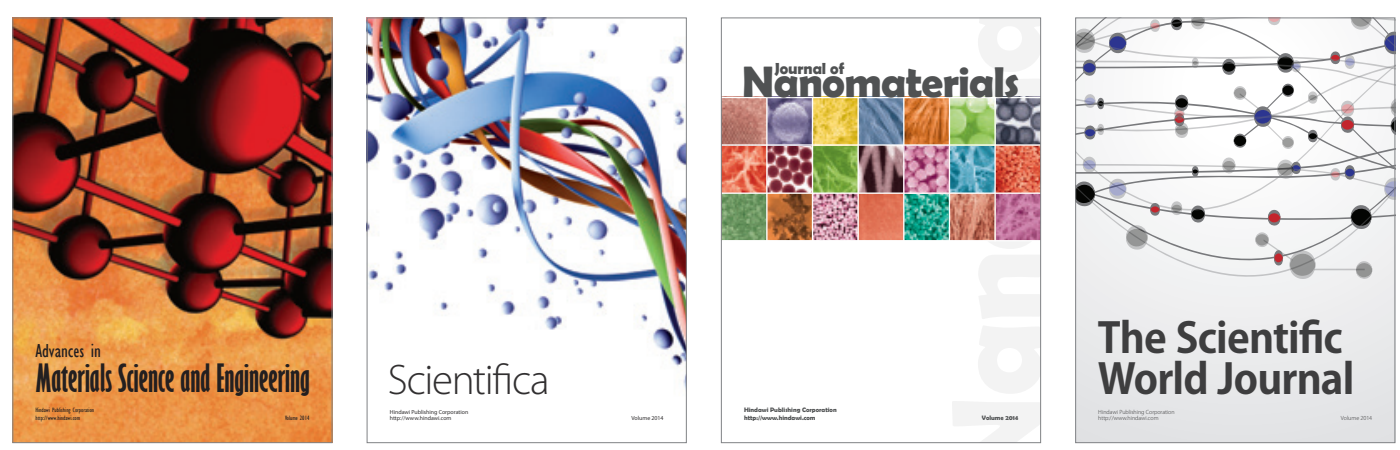

\section{The Scientific World Journal}
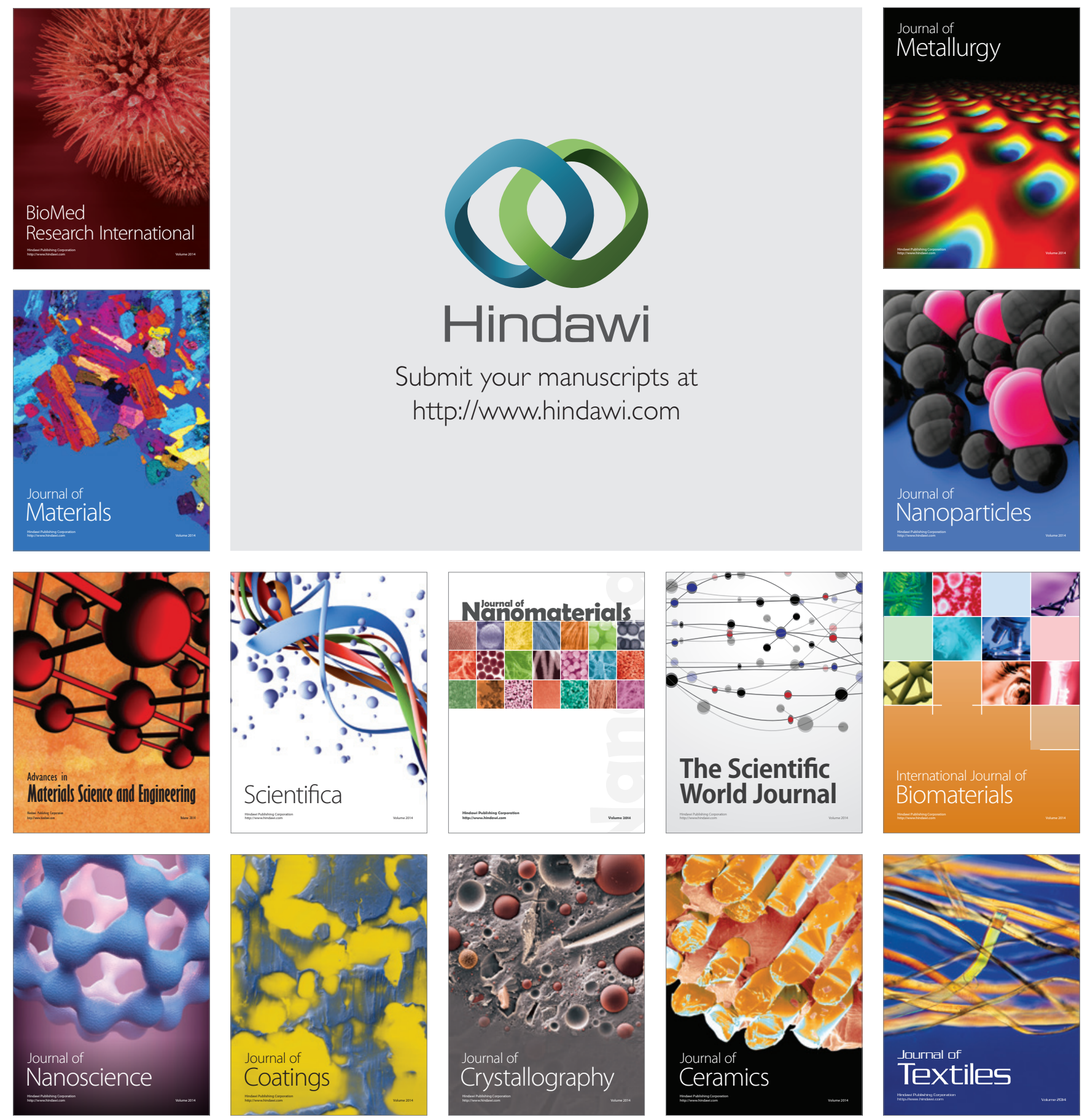